\title{
The Value and Growth Spreads: The Recent Cases in the Japanese Stock Markets
}

\author{
Chikashi Tsuji \\ Faculty of Economics, Chuo University \\ 742-1 Higashinakano Hachioji-shi, Tokyo 192-0393, Japan \\ E-mail: mail_sec_low@minos.ocn.ne.jp
}

Received: August 2, 2014 Accepted: August 13, $2014 \quad$ Published: October 5, 2014

doi:10.5296/bms.v5i2.6415 URL: http://dx.doi.org/10.5296/bms.v5i2.6415

\begin{abstract}
This study explores the recent performance of growth and value stocks by using the data of the Russell-Nomura Japan value and growth indices. This research is significantly important in order to judge the effectiveness of investment management and strategy in the recent Japanese equity markets. The recent full sample period under our analyses is from January 4, 2010 to March 20, 2014. Our investigations as to the value spreads, growth spreads, and value-growth spreads in Japan derive the following evidence. First, (1) in the recent Japanese stock markets, the value spreads over Tokyo Stock Price Index (TOPIX) are statistically significantly positive in all six Russell-Nomura Japan value indices. Second, (2) in the recent stock markets in Japan, the growth spreads over TOPIX are also statistically significantly positive in all six Russell-Nomura Japan growth indices. Third, (3) in our above full sample period, growth style indices generally outperform the value style indices, and in particular, after the inauguration of the new Abe cabinet in December 2012, smaller-size growth stock indices strongly outperform the same size category value indices.
\end{abstract}

Keywords: Growth spread, Russell-Nomura Japan Index, TOPIX, Value spread 


\section{Introduction}

The value premia in equity markets are often discussed not only in the US but also in other international countries; it is also well-known that behavioral finance gave psychological fundamental for the value premium (e.g., De Bondt and Thaler; 1985). Considering the recent Japanese stock markets, since the new Abe cabinet was inaugurated in Japan on December, 26, 2012, stock market conditions and market expectations would largely change. If this is the case, how is the state of the value and growth premia in the recent Japanese stock markets? In order to answer this question by using actual data, we empirically examine several Japanese value and growth stock indices. Inquiring into the existing studies, there are many preceding studies focusing on the value premium; however, as our literature review in the later section shows, little existing study focused on the growth premium in general, and in particular, as to Japan, it is rather difficult to find the preceding studies that focused on the growth premia or growth spreads.

Based on the state of existing literature and our above research motivation, this paper explores the performance of the growth and value stock indices by using the data of the Russell-Nomura Japan indices. Our investigations with regard to the value spreads, growth spreads, and value-growth spreads clarify the following evidence. First, (1) in the recent Japanese stock markets, the value spreads over Tokyo Stock Price Index (TOPIX) are statistically significantly positive in all six Russell-Nomura Japan value indices we analyze. Second, (2) in the recent stock markets in Japan, the growth spreads over TOPIX are also statistically significantly positive in all six Russell-Nomura Japan growth indices we investigate. Third, (3) in our full sample period from January 4, 2010 to March 20, 2014, growth style indices generally outperform the value style indices, and in particular, after the new Abe cabinet was inaugurated in December 2012, smaller-size growth stock indices outperform the same size category value stock indices. The rest of the paper is organized as follows. Section 2 reviews the existing literature; Section 3 explains our data; Section 4 describes our testing methodology. Section 5 then documents our results of empirical examinations and Section 6 summarizes the paper.

\section{Literature Review}

Reviewing recent studies as to the value premium first, Black et al. (2007) explored the long-run linkage among the value premium indices for G7 countries using the data for the period from January 1975 to December 2002. Their empirical analyses by using vector autoregressive models suggested that the value premia in G7 countries were potentially driven by the same fundamentals. Liu and Zhang (2008) analyzed the value spread and concluded that the value spread appeared much less useful for forecasting the US stock returns. They also commented that their findings cast doubt on the study of Campbell and Vuolteenaho (2004), which used the value spread as a predictor of aggregate stock returns. Further, Arisoy (2010) analyzed the value premium in the French stock markets. This study suggested that the systematic volatility risk was a significant driving factor of the value premium in the French equity markets. Baltussen et al. (2012) analyzed the US yearly data from 1963 to 2007, and concluded that the value premium was smaller for investors such as 
pension funds and insurance companies, especially when they were downside risk averse. Brailsford et al. (2012) examined the value premium in the Australian stock markets, and they suggested that the existence of the value premium depended on the portfolio formation methodology. They concluded that the state of the value premium in Australia was not always the same as that in the US stock markets. In addition, Fong (2012) reexamined the book-to-market effects by using the Livingston survey data of real GDP growth forecasts. As a result, this study concluded that none of the tests in this study provided robust evidence that the value premium could be explained by business risk. Further, Novy-Marx (2013) considered the value strategy in the US equity markets. This study concluded that when profitability, measured by gross profits-to-assets, is controlled, the performance of value strategies drastically increased, in particular, among the largest and highest liquidity shares.

Contrary to the value premium, little existing study focused on the growth premium. Searching for the literature related to the growth premium, Rytchkov (2010) investigated the return predictability of growth portfolios and value portfolios in the US. This study demonstrated that returns of growth and value portfolios were predictable, and the predictability was stronger for growth stocks. In addition, applying the filtering technique to the high-minus-low (HML) portfolio of Fama and French (1993), this research built a new forecaster for the value premium and suggested that this new forecaster seemed to be only weakly associated with business cycle variables. Further, Larsen and Munk (2012) developed a general theoretical framework to consider the growth/value tilts in dynamic asset allocation problems and concluded that among other things, for strategic investments, growth/value tilts were highly valuable. As above, many studies as to the value premium exist whilst there is little study focusing on the growth premium, and as to Japan, although Tsuji (2012) analyzed the small-size- and value-premia, it is especially difficult to find the international academic study that focused on the growth premia or growth spreads in Japan.

\section{Data}

This section describes the data that we analyze in this study. All Japanese stock index data except for TOPIX are from the Russell-Nomura Japan Index, and all data used in this paper are supplied by the QUICK Corp. Further, our full sample period is from January 4, 2010 to March 20, 2014. For our investigations, we first compute daily log return in terms of TOPIX, which is a benchmark of our study. Namely, the variable, DLTOPIX represents the first log difference of the TOPIX daily closing price and this variable is calculated as the percentage log return by multiplying 100 . For our analyses, when we construct stock return variables, we use the percentage log return for all variables with regard to the Japanese equity indices.

In addition to DLTOPIX, we compute and use six value index returns by using the Russell-Nomura Japan Index data as follows. First, DLOAV indicates the percentage log return computed by using the daily closing price of the Russell-Nomura Japanese overall value index; DLLV means the percentage log return of the Russell-Nomura Japanese large value index; DLMV indicates that of the Russell-Nomura Japanese middle value index; DLMSV denotes that of the Russell-Nomura Japanese middle-small value index; DLSV means that of the Russell-Nomura Japanese small value index; DLMICROV represents that 
of the Russell-Nomura Japanese micro value index.

Moreover, we also compute and use six growth index returns by using the Russell-Nomura Japan Index data. First, DLOAG indicates the percentage log return computed by using the daily closing price of the Russell-Nomura Japanese overall growth index; DLLG means the percentage log return of the Russell-Nomura Japanese large growth index; DLMG represents that of the Russell-Nomura Japanese middle growth index; DLMSG indicates that of the Russell-Nomura Japanese middle-small growth index; DLSG is that of the Russell-Nomura Japanese small growth index; DLMICROG represents that of the Russell-Nomura Japanese micro growth index.

Furthermore, we further compute and use two kinds of adjusted stock index price spreads. First are twelve value- and growth-spreads over TOPIX, and second are six spreads of value indices over growth indices. In order to calculate the value- and growth-spreads over TOPIX, we first adjust the values of TOPIX and the twelve indices so that their values equal to 100 on January 4, 2010, and then calculate the twelve price-spreads as follows. Documenting six value-spreads first, OAVSP means the difference of the adjusted Russell-Nomura Japanese overall value index value minus the adjusted TOPIX value; LVSP denotes the difference of the adjusted Russell-Nomura Japanese large value index value minus the adjusted TOPIX value; MVSP denotes the difference of the adjusted Russell-Nomura Japanese middle value index value minus the adjusted TOPIX value; MSVSP denotes the difference of the adjusted Russell-Nomura Japanese middle-small value index value minus the adjusted TOPIX value; SVSP indicates the difference of the adjusted Russell-Nomura Japanese small value index value minus the adjusted TOPIX value; MICROVSP means the difference of the adjusted Russell-Nomura Japanese micro value index value minus the adjusted TOPIX value.

Next are six growth-spreads: OAGSP means the difference of the adjusted Russell-Nomura Japanese overall growth index value minus the adjusted TOPIX value; LGSP is the difference of the adjusted Russell-Nomura Japanese large growth index value minus the adjusted TOPIX value; MGSP denotes the difference of the adjusted Russell-Nomura Japanese middle growth index value minus the adjusted TOPIX value; MSGSP is the difference of the adjusted Russell-Nomura Japanese middle-small growth index value minus the adjusted TOPIX value; SGSP indicates the difference of the adjusted Russell-Nomura Japanese small growth index value minus the adjusted TOPIX value; MICROGSP indicates the difference of the adjusted Russell-Nomura Japanese micro growth index value minus the adjusted TOPIX value.

Finally, we compute six value spreads over growth indices as follows: OAVGSP is the difference of the adjusted Russell-Nomura Japanese overall value minus overall growth index value; LVGSP denotes the difference of the adjusted Russell-Nomura Japanese large value minus large growth index value; MVGSP is the difference of the adjusted Russell-Nomura Japanese middle value minus middle growth index value; MSVGSP denotes the difference of the adjusted Russell-Nomura Japanese middle-small value minus middle-small growth index value; SVGSP means the difference of the adjusted Russell-Nomura Japanese small value minus small growth index value; MICROVGSP indicates the difference of the adjusted Russell-Nomura Japanese micro value minus micro growth index value. 
Table 1. Descriptive statistics for the daily log stock price index returns

Panel A. Statistics for value index returns with TOPIX return

\begin{tabular}{lllll}
\hline & DLTOPIX & DLOAV & DLLV & DLMV \\
\hline Mean & 0.0225 & 0.0293 & 0.0251 & 0.0263 \\
Median & 0.0333 & 0.0558 & 0.0172 & 0.0269 \\
Mean (annualized) & 5.6783 & 7.3856 & 6.3149 & 6.6277 \\
Std. Dev. & 1.3003 & 1.3555 & 1.3842 & 1.3886 \\
Skewness & -0.7514 & -0.8408 & -0.7048 & -0.9595 \\
Kurtosis & 5.8210 & 6.8256 & 5.6106 & 7.8274 \\
Obs. & 1035 & 1035 & 1035 & 1035 \\
\hline
\end{tabular}

\begin{tabular}{llll}
\hline & DLMSV & DLSV & DLMICROV \\
\hline Mean & 0.0334 & 0.0441 & 0.0510 \\
Median & 0.0667 & 0.1214 & 0.1468 \\
Mean (annualized) & 8.4229 & 11.1240 & 12.8625 \\
Std. Dev. & 1.3460 & 1.3075 & 1.2851 \\
Skewness & -1.1034 & -1.3056 & -1.6213 \\
Kurtosis & 9.4196 & 12.0424 & 16.6391 \\
Obs. & 1035 & 1035 & 1035
\end{tabular}

Panel B. Statistics for growth index returns

\begin{tabular}{llll}
\hline & DLOAG & DLLG & DLMG \\
\hline Mean & 0.0332 & 0.0319 & 0.0321 \\
Median & 0.0337 & 0.0171 & 0.0591 \\
Mean (annualized) & 8.3696 & 8.0380 & 8.0874 \\
Std. Dev. & 1.2522 & 1.2667 & 1.2405 \\
Skewness & -0.6353 & -0.5636 & -0.7864 \\
Kurtosis & 4.8078 & 4.0984 & 7.4099 \\
Obs. & 1035 & 1035 & 1035 \\
\hline & DLMSG & DLSG & DLMICROG \\
\hline Mean & 0.0347 & 0.0453 & 0.0403 \\
Median & 0.0686 & 0.1109 & 0.1315 \\
Mean (annualized) & 8.7559 & 11.4246 & 10.1580 \\
Std. Dev. & 1.2234 & 1.2294 & 1.3269 \\
Skewness & -0.9145 & -1.4462 & -1.9671 \\
Kurtosis & 8.8290 & 14.7431 & 20.1271 \\
Obs. & 1035 & 1035 & 1035
\end{tabular}

Notes: In this table, the variable descriptive statistics are displayed. Our full sample period spans January 4, 2010 to March 20, 2014. Further, Std. Dev. means the value of standard deviation and Obs. indicates the number of the observations in our full sample period. 
Table 1 exhibits the descriptive statistics for our twelve log returns of value and growth indices and TOPIX log return. Interestingly, all return variables show negative values of skewness and larger values of kurtosis than that of normal distribution. Further, Figure 1 displays the daily time-series dynamics of six value-spreads over TOPIX. More specifically, Panel A exhibits the overall value-spreads over TOPIX; Panel B displays the large-size value-spreads over TOPIX; Panel $\mathrm{C}$ shows the middle-size value-spreads over TOPIX; Panel D exhibits the middle-small-size value-spreads over TOPIX; Panel E displays the small-size value-spreads over TOPIX; Panel F shows the micro-size value-spreads over TOPIX. Figure 1 indicates that small- and micro-size value spreads over TOPIX gradually increase during our full sample period in general; on the other hand, other value spreads drop around September 2012, and then recover and generally increase towards the end of our sample period.

Moreover, Figure 2 exhibits the daily time-series dynamics of six growth-spreads over TOPIX. More specifically, Panel A shows the overall growth-spreads over TOPIX; Panel B displays the large-size growth-spreads over TOPIX; Panel C shows the middle-size growth-spreads over TOPIX; Panel D displays the middle-small-size growth-spreads over TOPIX; Panel E exhibits the small-size growth-spreads over TOPIX; Panel F demonstrates the micro-size growth-spreads over TOPIX. In Figure 2, we understand that in general, all growth-spreads over TOPIX gradually and continuously increase during our full sample period.

\section{Methodology}

Describing our statistical testing methodology, we first examine whether our six value-spreads over TOPIX are statistically significantly different from zero for our full sample period. Then we also scrutinize whether our six growth-spreads over TOPIX are statistically significantly different from zero for our full sample period. After these tests, we further investigate our six value-growth spreads. Specifically, we first examine whether our six value-growth spreads are statistically significantly positive or negative for our full sample period. Finally, we further scrutinize whether our six value-growth spreads are statistically significantly positive or negative for the sub-sample period after the inauguration of the new Abe cabinet on December 26, 2012. Namely, this sub-sample period spans December 26, 2012 to March 20, 2014, and this test is particularly interesting since the test results inform us the effective equity investment style after the inauguration of the new cabinet in Japan.

In all above tests, we use $z$-tests; we examine whether the average spread values are statistically significantly positive or negative. In Figure 3, we graphically display the daily time-series dynamics of our six value-growth spreads. More concretely, Panel A exhibits the overall value-growth spreads; Panel B displays the large-size value-growth spreads; Panel C displays the middle-size value-growth spreads; Panel D exhibits the middle-small-size value-growth spreads; Panel E indicates the small-size value-growth spreads; Panel F shows the micro-size value-growth spreads. By viewing Figure 3, we understand that except for the micro-size value-growth spreads, all value-growth spreads gradually and continuously decrease during our full sample period in general. 
Panel A. Overall value-spread

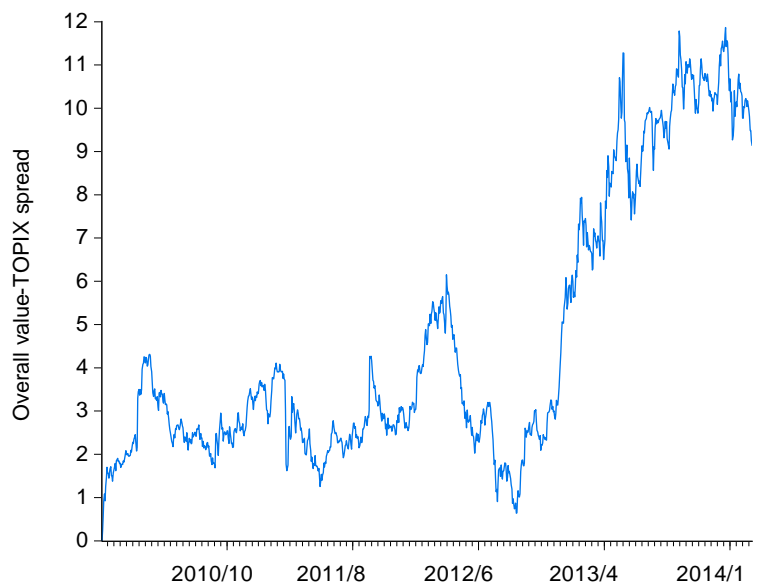

Panel C. Middle value-spread

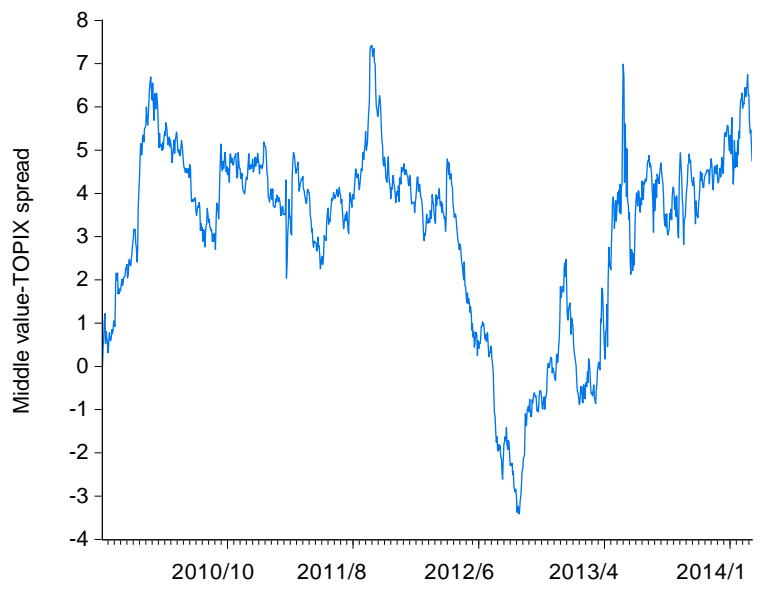

Panel E. Small value-spread

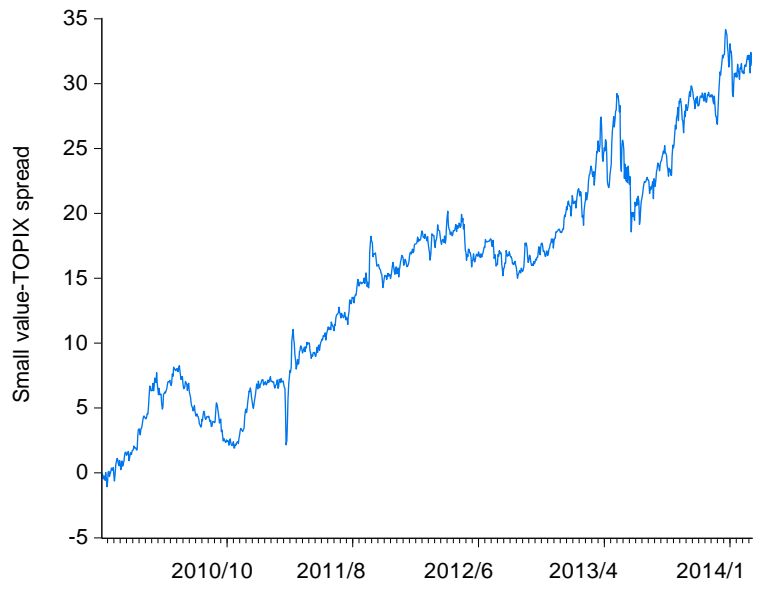

Panel B. Large value-spread

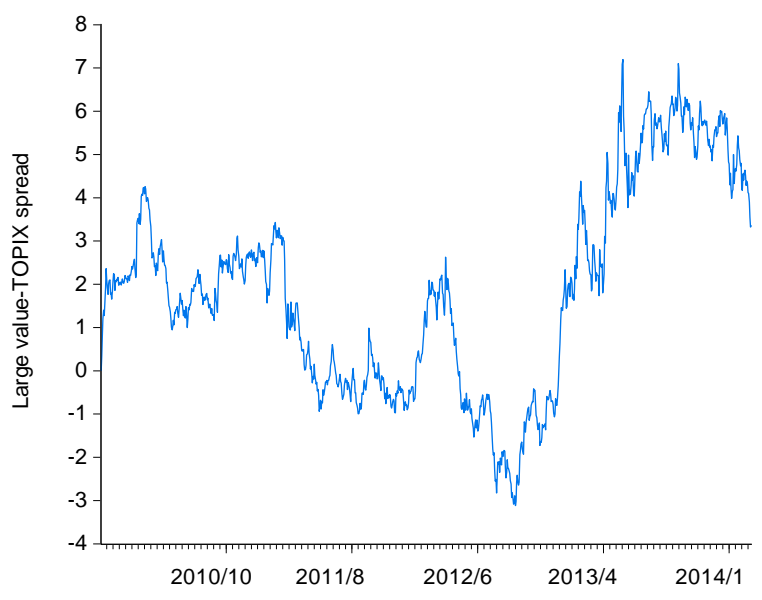

Panel D. Middle-small value-spread

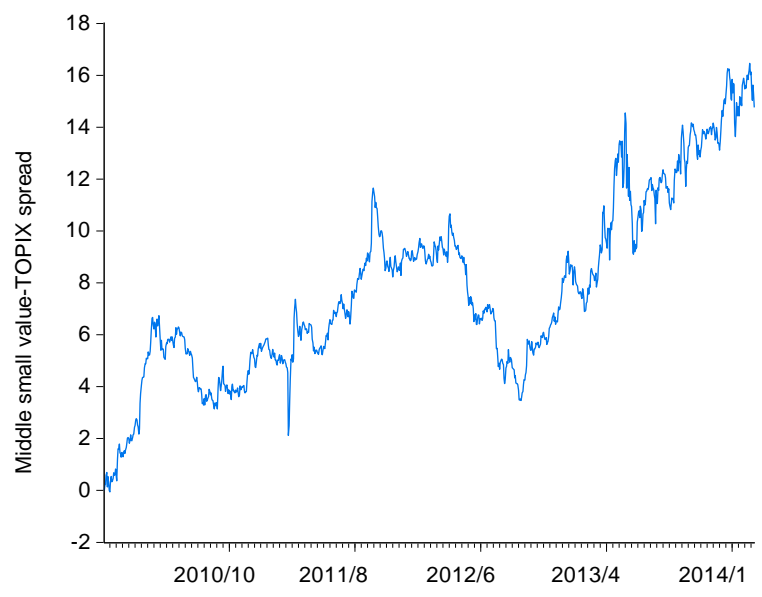

Panel F. Micro value-spread

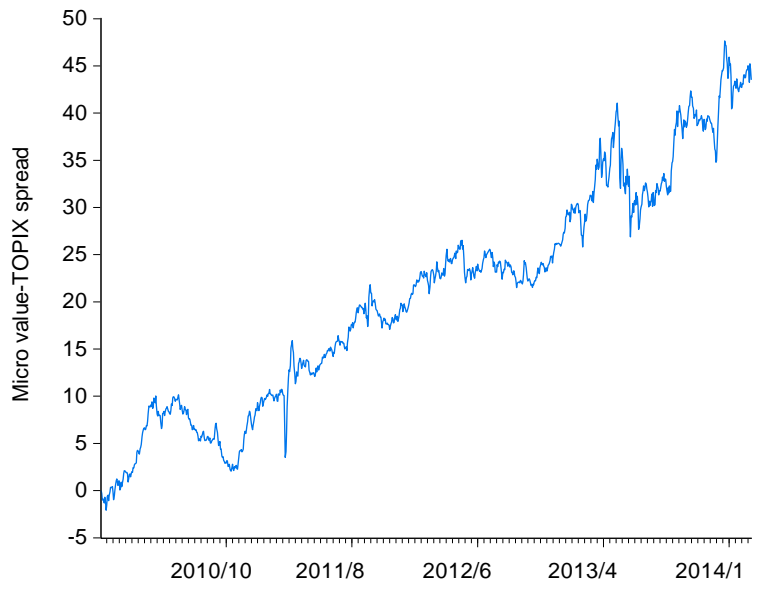

Figure 1. The value spreads: the daily time-series evolution of six value-spreads over TOPIX for the period from January 4, 2010 to March 20, 2014 
Panel A. Overall growth-spread

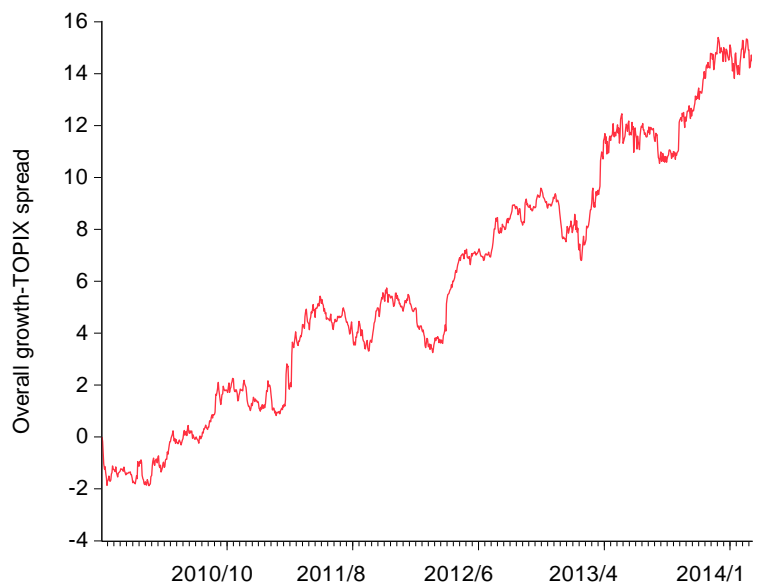

Panel C. Middle growth-spread

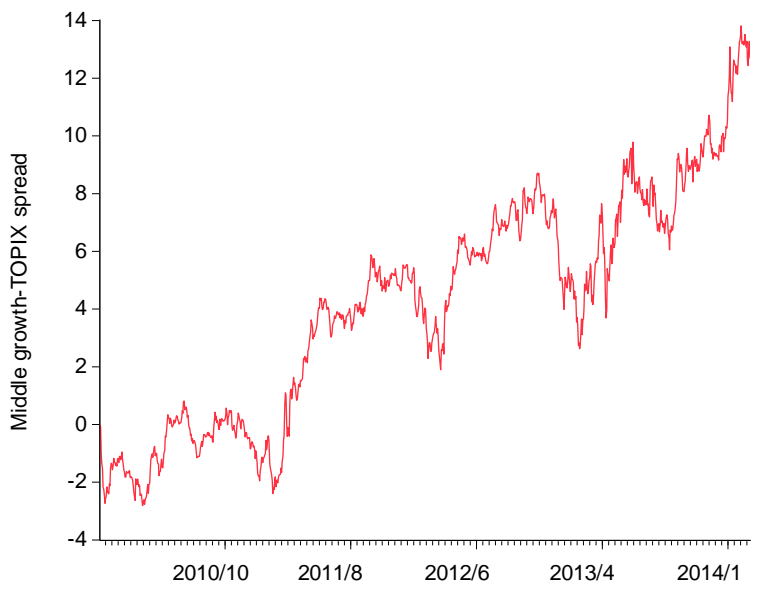

Panel E. Small growth-spread

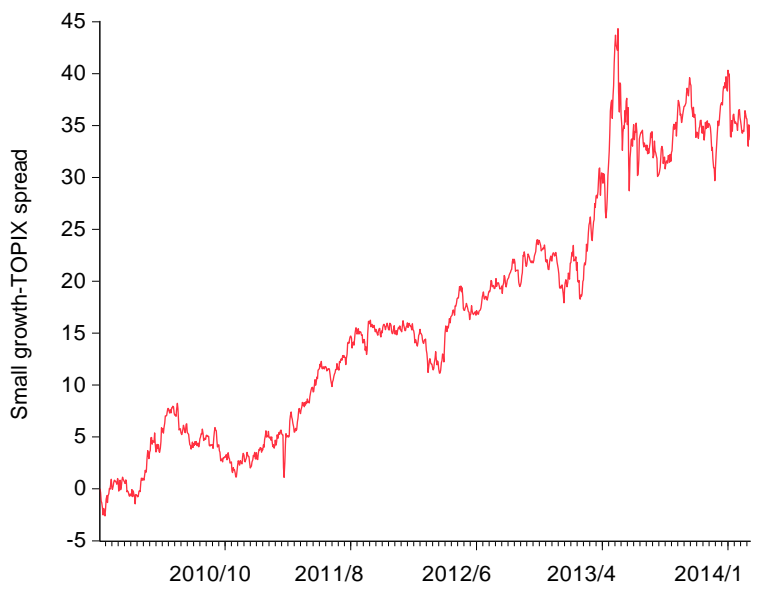

Panel B. Large growth-spread

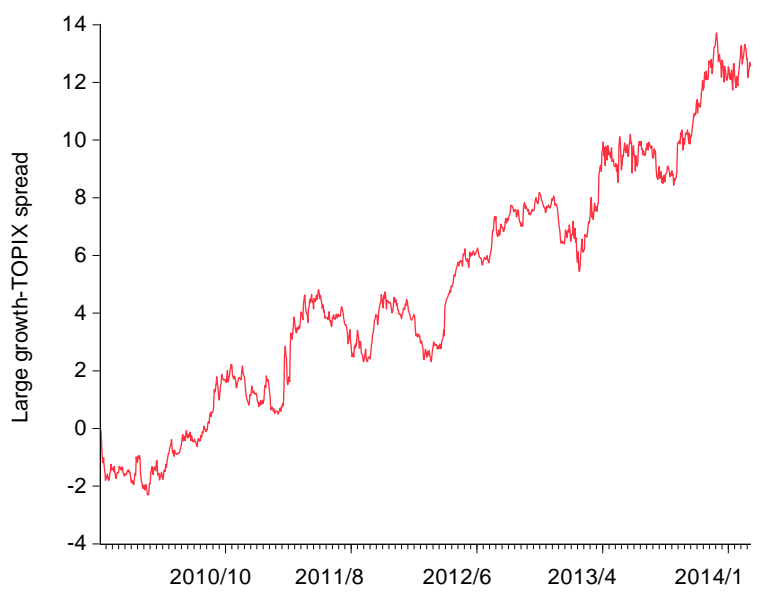

Panel D. Middle-small growth-spread

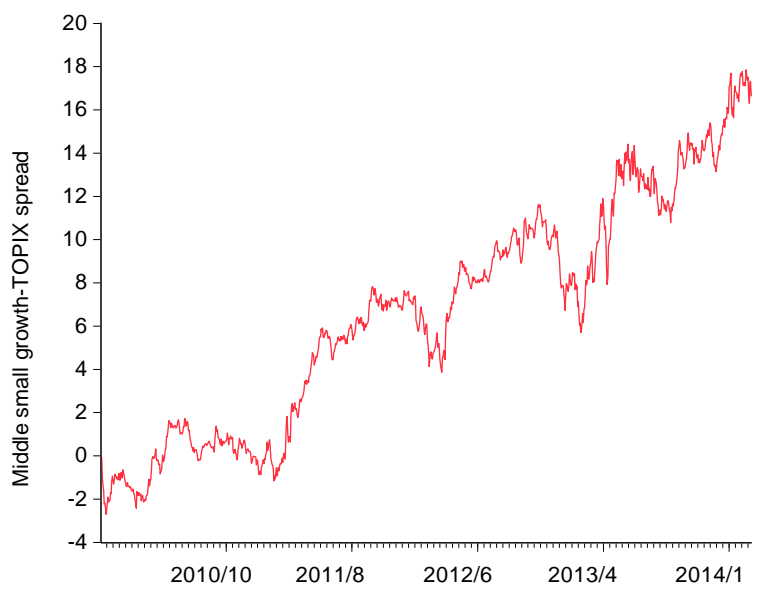

Panel F. Micro growth-spread

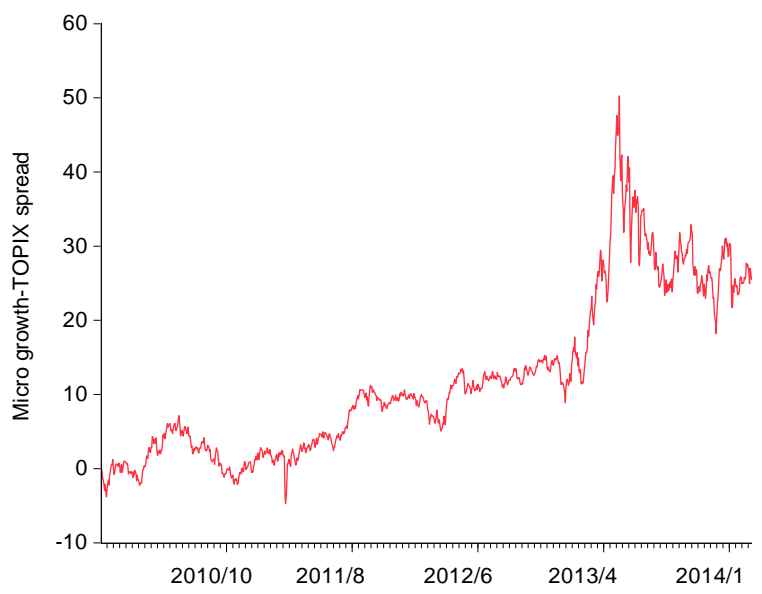

Figure 2. The growth spreads: the daily time-series evolution of six growth-spreads over TOPIX for the period from January 4, 2010 to March 20, 2014 


\section{Empirical Results}

\subsection{Testing the Value and Growth Spreads over TOPIX}

This subsection explains our empirical results for our six value- and six growth-spreads over TOPIX. First, our $z$-test results for the value-spreads and growth-spreads are displayed in Panels A and B of Table 2, respectively. From Panel A of this table, we understand that all the Russell-Nomura Japan Index value-spreads over TOPIX are statistically significantly positive for our full sample period, and in particular, the average spread values in terms of the small-size value-spread and the micro-size value-spread are relatively large (They are 15.2406 and 20.6497 points, respectively.). Second, from Panel B of Table 2, we understand that all the Russell-Nomura Japan Index growth-spreads over TOPIX are also statistically significantly positive for our full sample period, and in particular, the average spread values in terms of the small-size growth-spread and the micro-size growth-spread are relatively large (They are 16.9022 and 12.0068 points, respectively.).

\subsection{Testing the Spreads of Value over Growth Indices}

This subsection explains our empirical results for our six value-growth spreads. More specifically, our $z$-test results for the value-growth spreads for our full sample period are displayed in Panel A of Table 3, and our $z$-test results for the value-growth spreads for our sub-sample period after the inauguration of the new Abe cabinet are shown in Panel B of Table 3, respectively. For the tests in Panel B, we adjust the values of six value- and six growth-indices so that their values equal to 100 on December 26, 2012, and then compute the six value-growth adjusted price-spreads, OAVGSP, LVGSP, MVGSP, MSVGSP, SVGSP, and MICROVGSP.

First, Panel A of Table 3 indicates that for our full sample period, all the Russell-Nomura Japan growth indices demonstrate statistically significantly higher performance than the value indices except for the middle-small-growth and micro-growth indices. In addition, for the period after the inauguration of the new Abe cabinet, as we understand from Panel B of Table 3, all the Russell-Nomura Japan growth indices demonstrate statistically significantly higher performance than the value indices except for the overall-growth and large-growth indices.

Comparing the results of our full sample period with those of the sub-sample period after the new cabinet inauguration in Japan, first, (1) the average middle-small value-growth spread of 1.1666 point in Panel A turns to -1.9324 in Panel B; (2) the average small-size value-growth spread of -1.6616 point in Panel A turns to -5.6603 in Panel B; (3) the average micro-size value-growth spread of 8.6429 point in Panel A changes to -11.7647 in Panel B. Thus we understand that, in particular, middle-small-, small-, and micro-size Russell-Nomura growth indices demonstrate especially higher performance in the period after the new Abe cabinet was inaugurated.

To sum up, in the recent stock markets in Japan, growth style indices generally outperformed the value style indices. In particular, after the new Abe cabinet was inaugurated in December 2012, in the Japanese equity markets, growth style investment strategy was much more effective than value strategy in smaller-size stock portfolios. 
Table 2. Test results for the value and growth spreads

Panel A. Test results for the value spreads

\begin{tabular}{llll}
\hline & OAVSP & LVSP & MVSP \\
\hline Mean & $4.6497^{* * *}$ & $1.8553 * * *$ & $3.1112^{* * *}$ \\
Median & 3.1061 & 1.8437 & 3.7996 \\
Standard deviation & 3.1397 & 2.3677 & 2.1757 \\
Skewness & 0.9336 & 0.2026 & -0.9438 \\
Kurtosis & -0.6453 & -0.8518 & 0.2240 \\
Test statistic & 47.6445 & 25.2082 & 46.0038 \\
$p$-value & 0.0000 & 0.0000 & 0.0000 \\
\hline & MSVSP & SVSP & MICROVSP \\
\hline Mean & $7.7537 * * *$ & $15.2406^{* * *}$ & $20.6497 * * *$ \\
Median & 7.0146 & 16.3923 & 22.0252 \\
Standard deviation & 3.5747 & 8.6998 & 12.1469 \\
Skewness & 0.3977 & 0.0797 & 0.1527 \\
Kurtosis & -0.3954 & -0.8931 & -0.8844 \\
Test statistic & 69.7811 & 56.3589 & 54.6915 \\
$p$-value & 0.0000 & 0.0000 & 0.0000 \\
\hline
\end{tabular}

Panel B. Test results for the growth spreads

\begin{tabular}{llll}
\hline & OAGSP & LGSP & MGSP \\
\hline Mean & $5.9633 * * *$ & $4.8908^{* * * *}$ & $4.1670 * * *$ \\
Median & 5.2539 & 4.3694 & 4.6654 \\
Standard deviation & 4.8008 & 4.1514 & 3.9247 \\
Skewness & 0.1691 & 0.1346 & 0.0145 \\
Kurtosis & -1.0114 & -0.9283 & -0.8372 \\
Test statistic & 39.9613 & 37.9012 & 34.1578 \\
$p$-value & 0.0000 & 0.0000 & 0.0000 \\
\hline & MSGSP & SGSP & MICROGSP \\
\hline Mean & $6.5871 * * *$ & $16.9022^{* * *}$ & $12.0068 * * *$ \\
Median & 7.0266 & 15.5611 & 9.8499 \\
Standard deviation & 5.3307 & 11.8861 & 10.9829 \\
Skewness & 0.0670 & 0.3461 & 0.8725 \\
Kurtosis & -1.0432 & -1.0241 & -0.0817 \\
Test statistic & 39.7539 & 45.7482 & 35.1706 \\
$p$-value & 0.0000 & 0.0000 & 0.0000 \\
\hline
\end{tabular}

Notes: This table displays the results of our $z$-tests with regard to the mean spread values. The period under our analyses is from January 4, 2010 to March 20, 2014. *** denotes the statistical significance of the mean spread value at the $1 \%$ level. 
Panel A. Overall value-growth spread

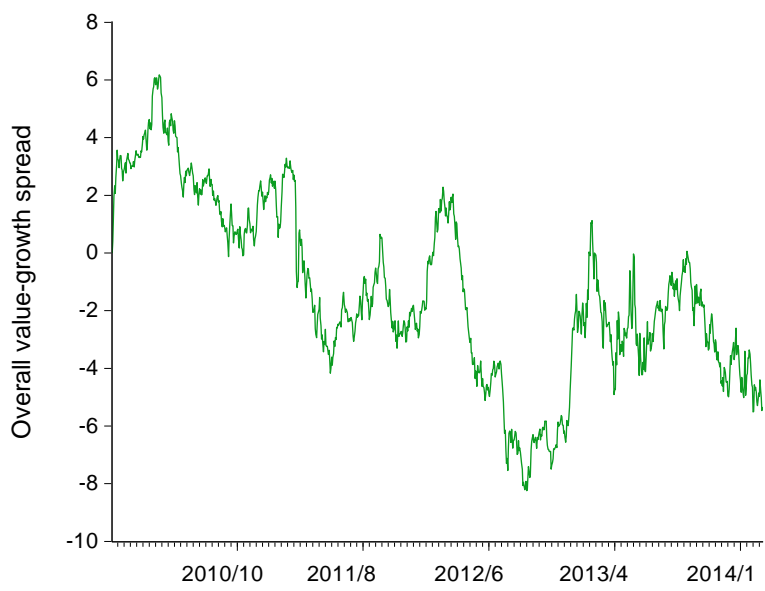

Panel C. Middle value-growth spread

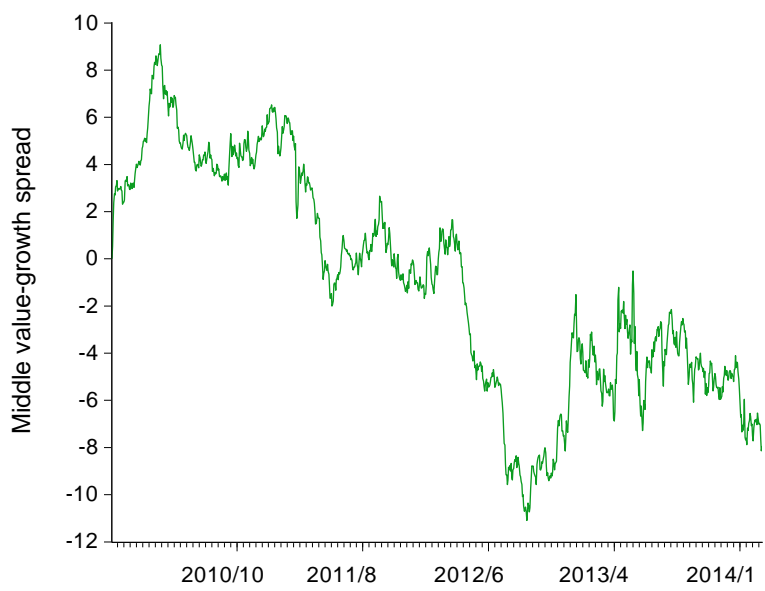

Panel E. Small value-growth spread

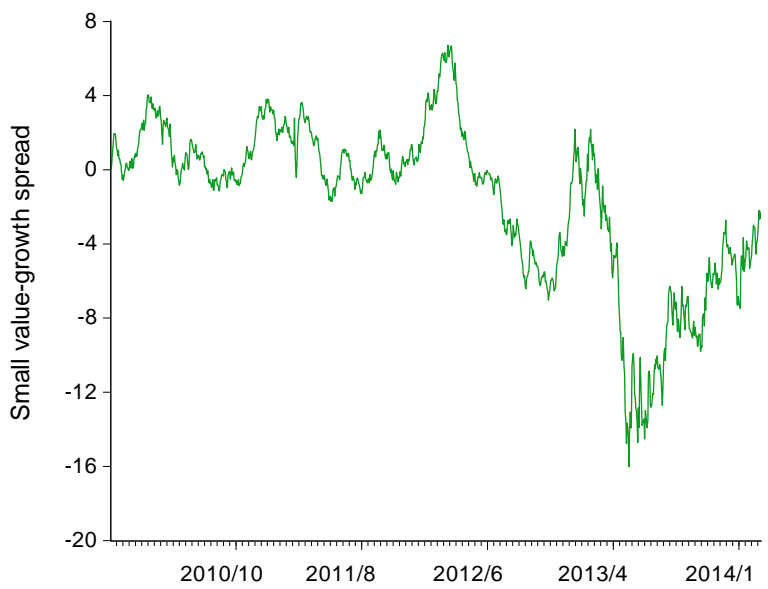

Panel B. Large value-growth spread

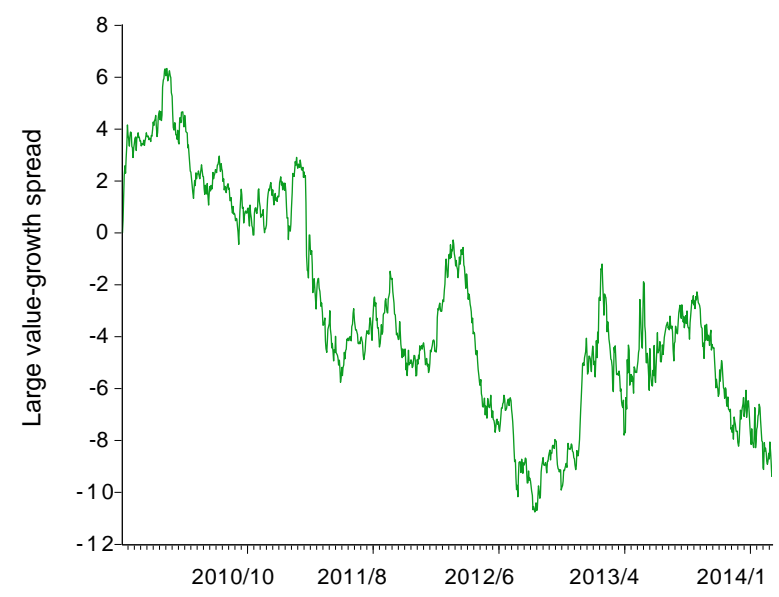

Panel D. Middle-small value-growth spread

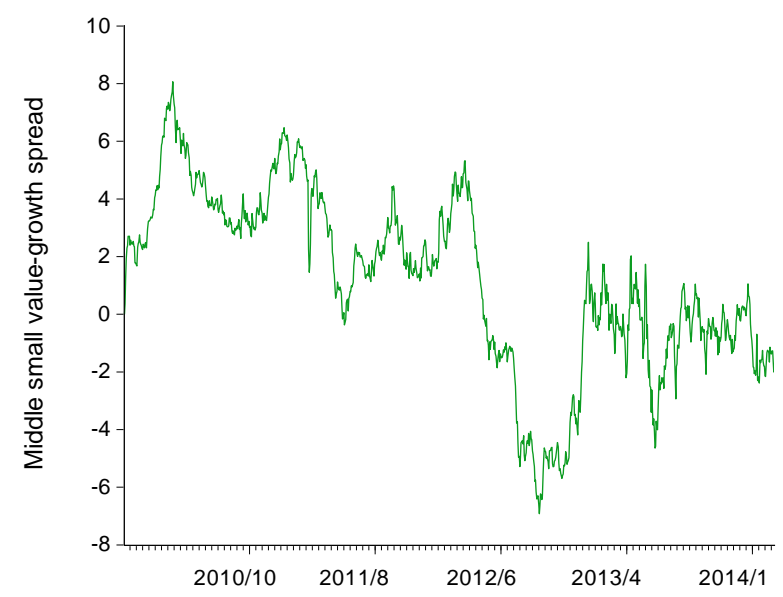

Panel F. Micro value-growth spread

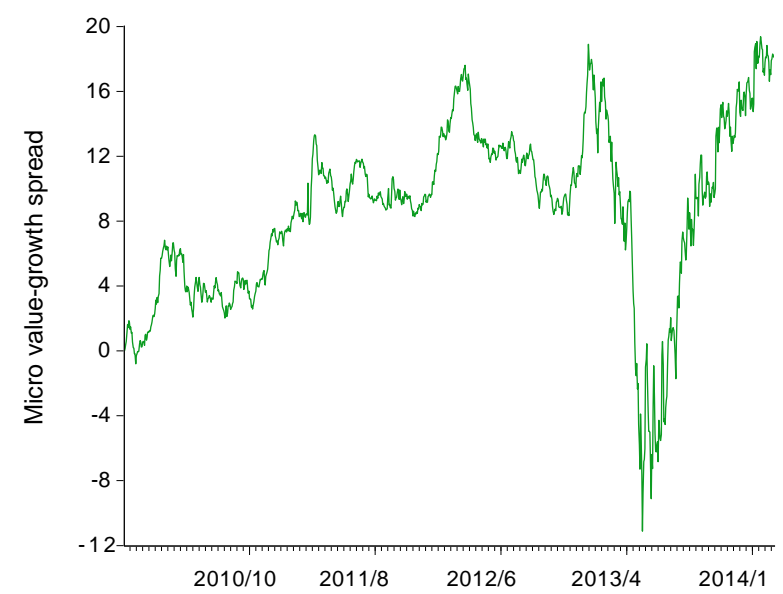

Figure 3. The value-growth spreads: the daily time-series evolution of six value-growth spreads for the period from January 4, 2010 to March 20, 2014 
Table 3. Test results for the value minus growth spreads

Panel A. Test results for the full sample period from January 4, 2010 to March 20, 2014

\begin{tabular}{llll}
\hline & OAVGSP & LVGSP & MVGSP \\
\hline Mean & $-1.3136^{* * *}$ & $-3.0356^{* * *}$ & $-1.0558^{* * *}$ \\
Median & -1.8191 & -3.8561 & -0.9532 \\
Standard deviation & 3.1420 & 4.0619 & 4.7785 \\
Skewness & 0.1159 & 0.3241 & 0.0132 \\
Kurtosis & -0.6462 & -0.8315 & -1.0681 \\
Test statistic & 13.4496 & 24.0423 & 7.1082 \\
$p$-value & 0.0000 & 0.0000 & 0.0000 \\
\hline & MSVGSP & SVGSP & MICROVGSP \\
\hline Mean & $1.1666^{* * *}$ & $-1.6616^{* * *}$ & $8.6429 * * *$ \\
Median & 1.4498 & -0.3876 & 9.3778 \\
Standard deviation & 3.0910 & 4.4006 & 5.3596 \\
Skewness & -0.3481 & -0.9045 & -0.6008 \\
Kurtosis & -0.4088 & 0.3550 & 0.3609 \\
Test statistic & 12.1419 & 12.1474 & 51.8796 \\
$p$-value & 0.0000 & 0.0000 & 0.0000 \\
\hline
\end{tabular}

Panel B. Test results for the period after the inauguration of the new Abe cabinet

\begin{tabular}{llll}
\hline & OAVGSP & LVGSP & MVGSP \\
\hline Mean & $0.5194 * * *$ & $1.4462^{* * *}$ & $-0.9442^{* * *}$ \\
Median & 0.3908 & 1.3061 & -0.8819 \\
Standard deviation & 1.3374 & 1.7616 & 1.4942 \\
Skewness & 0.1690 & -0.0333 & 0.0883 \\
Kurtosis & -0.5622 & -0.7352 & -0.2552 \\
Test statistic & 6.7263 & 14.2190 & 10.9442 \\
$p$-value & 0.0000 & 0.0000 & 0.0000 \\
\hline & MSVGSP & SVGSP & MICROVGSP \\
\hline Mean & $-1.9324 * * *$ & $-5.6603 * * *$ & $-11.7647 * * *$ \\
Median & -1.8173 & -5.4156 & -10.6051 \\
Standard deviation & 1.2140 & 3.7178 & 7.5400 \\
Skewness & -0.4148 & -0.0383 & -0.5887 \\
Kurtosis & 0.5218 & -0.6882 & -0.3706 \\
Test statistic & 27.5714 & 26.3704 & 27.0255 \\
$p$-value & 0.0000 & 0.0000 & 0.0000
\end{tabular}

Notes: This table displays the results of our $z$-tests with regard to the mean spread values. The period under our analyses is from January 4, 2010 to March 20, 2014 in Panel A and from December 26, 2012 to March 20, 2014 in Panel B. *** denotes the statistical significance of the mean spread value at the $1 \%$ level. 


\section{Conclusions}

This paper explored the performance of the growth and value stock indices by using the data of the Russell-Nomura Japan value and growth indices. Our investigations regarding the value spreads, growth spreads, and value-growth spreads revealed the following findings. First, (1) in the recent Japanese stock markets, value spreads over TOPIX were statistically significantly positive as to all six Russell-Nomura Japan value indices we analyzed. Second, (2) in the recent stock markets in Japan, growth spreads over TOPIX were also statistically significantly positive with regard to all six Russell-Nomura Japan growth indices we investigated. These two kinds of findings indicate the effectiveness of active investment styles of value and growth investment strategies in the recent Japanese stock markets.

Finally, (3) in our full sample period from January 4, 2010 to March 20, 2014, growth style indices generally outperformed the same size category value indices, and in particular, after the new Abe cabinet was inaugurated in December 2012, smaller size Russell-Nomura growth indices highly outperformed the same size category value indices. This evidence clearly demonstrates the importance of stock size selections and investment style determinations in accordance with the market conditions.

As our empirical study suggested, therefore, judging the suitable investment style is significantly important in planning the successful investment strategy. As the philosophy of behavioral finance implies, it is suggested that considering the value investing is important in many cases, or regardless of business cycle phases; however, our investigations indicated that, especially for the period after the new Abe cabinet was inaugurated, smaller growth stocks demonstrated much better performance than smaller value stocks. We consider that, as Liu and Zhang (2008), Fong (2012), and Rytchkov (2010) pointed out, this evidence also indicates the importance of careful investigations of the relations among value stock performances, growth stock performances, and the phases of business cycles. Thus in order to construct smarter investment management strategy, we should accumulate the knowledge and sense for grasping the relationship between the state of actual market trends and conditions and fund performances; related further researches are my future tasks.

\section{Acknowledgements}

I am particularly grateful to the kind repeated invitation from the journal to write to this journal. In addition, I greatly thank the Editor and anonymous reviewers for their kind comments to this paper. I also appreciate the Japan society for the promotion of science and the Chuo university grant for special research for their generous financial assistance to this research.

\section{References}

Arisoy, Y. E. (2010). Volatility risk and the value premium: Evidence from the French stock market. Journal of Banking \& Finance, 34, 975-983. http://dx.doi.org/10.1016/j.jbankfin.2009.10.012

Baltussen, G., Post, G. T., \& van Vliet, P. (2012). Downside risk aversion, fixed-income 
exposure, and the value premium puzzle. Journal of Banking \& Finance, 36, 3382-3398. http://dx.doi.org/10.1016/j.jbankfin.2012.07.020

Black, A. J., Fraser, P., \& McMillan, D. G (2007). Are international value premiums driven by the same set of fundamentals? International Review of Economics and Finance, 16, 113-129. http://dx.doi.org/10.1016/j.iref.2005.05.002

Brailsford, T., Gaunt, C., \& O'Brien, M. A. (2012). The investment value of the value premium. Pacific-Basin Finance Journal, 20, 416-437. http://dx.doi.org/10.1016/j.pacfin.2011.12.008

Campbell, J. Y., \& Vuolteenaho, T. (2004). Bad beta, good beta. American Economic Review, 94, 1249-1275. http://dx.doi.org/10.1257/0002828043052240

De Bondt, W. F. M., \& Thaler, R. (1985). Does the stock market overreact? Journal of Finance, 40, 793-805. http://dx.doi.org/10.1111/j.1540-6261.1985.tb05004.x

Fama, E. F., \& French, K. R. (1993). Common risk factors in the returns on stocks and bonds. Journal of Financial Economics, 33, 3-56. http://dx.doi.org/10.1016/0304-405X(93)90023-5

Fong, W. M. (2012). Do expected business conditions explain the value premium? Journal of Financial Markets, 15, 181-206. http://dx.doi.org/10.1016/j.finmar.2011.08.004

Larsen, L. S., \& Munk, C. (2012). The costs of suboptimal dynamic asset allocation: General results and applications to interest rate risk, stock volatility risk, and growth/value tilts. Journal of Economic Dynamics \& Control, 36, 266-293. http://dx.doi.org/10.1016/j.jedc.2011.09.009

Liu, N., \& Zhang, L. (2008). Is the value spread a useful predictor of returns? Journal of Financial Markets, 11, 199-227. http://dx.doi.org/10.1016/j.finmar.2008.01.003

Novy-Marx, R. (2013). The other side of value: The gross profitability premium. Journal of Financial Economics, 108, 1-28. http://dx.doi.org/10.1016/j.jfineco.2013.01.003

Rytchkov, O. (2010). Expected returns on value, growth, and HML. Journal of Empirical Finance, 17, 552-565. http://dx.doi.org/10.1016/j.jempfin.2010.04.003

Tsuji, C. (2012). Positive return premia in Japan. Quantitative Finance, 12, 345-367. http://dx.doi.org/10.1080/14697688.2010.541485

\section{Copyright Disclaimer}

Copyright reserved by the author(s).

This article is an open-access article distributed under the terms and conditions of the Creative Commons Attribution license (http://creativecommons.org/licenses/by/3.0/). 